\title{
Blaise Cendrars, Raymone Duchâteau, Correspondance 1937-1954. «Sans ta carte je pourrais me croire sur une autre planète»
}

\section{Riccardo Benedettini}

\section{(2) OpenEdition}

\section{Journals}

\section{Edizione digitale}

URL: http://journals.openedition.org/studifrancesi/4461

DOI: 10.4000/studifrancesi.4461

ISSN: 2421-5856

\section{Editore}

Rosenberg \& Sellier

\section{Edizione cartacea}

Data di pubblicazione: 1 settembre 2016

Paginazione: 361

ISSN: 0039-2944

\section{Notizia bibliografica digitale}

Riccardo Benedettini, « Blaise Cendrars, Raymone Duchâteau, Correspondance 1937-1954. «Sans ta carte je pourrais me croire sur une autre planète» », Studi Francesi [Online], 179 (LX | II) | 2016, online dal 01 septembre 2016, consultato il 18 septembre 2020. URL : http://journals.openedition.org/ studifrancesi/4461 ; DOI : https://doi.org/10.4000/studifrancesi.4461

Questo documento è stato generato automaticamente il 18 settembre 2020.

\section{cc) (†) $\odot$}

Studi Francesi è distribuita con Licenza Creative Commons Attribuzione - Non commerciale - Non opere derivate 4.0 Internazionale. 


\title{
Blaise Cendrars, Raymone Duchâteau, Correspondance 1937-1954. «Sans ta carte je pourrais me croire sur une autre planète»
}

\author{
Riccardo Benedettini
}

\section{NOTIZIA}

BLAISE CENDRARS, RAYMONE DUCHÂTEAU, Correspondance 1937-1954. «Sans ta carte je pourrais me croire sur une autre planète», texte établi, annoté et présenté par Myriam Boucharenc, Carouge-Genève, Zoé, 2015, «Cendrars en toutes lettres», 592 pp.

1 Di particolare interesse l'uscita di questa corrispondenza che permetterà di meglio conoscere la vita e l'opera di Cendrars, poeta, romanziere, autore di mémoires, giornalista, nonché fotografo, cineasta, pittore e anche uomo che amava le donne. Le lettere qui raccolte - che seguono i precedenti volumi dedicati alla corrispondenza tra Cendrars e Poulaille, Guiette e Miller, insomma un Cendrars en toutes lettres, come scrive Miriam Cendrars nell'«Avant-propos» (pp. 5-6) - sono infatti quelle che lo scrittoresoldato ha inviato, negli anni 1937-1954, a Raymone Duchâteau, la compagna di una vita che, si legge nel portrait di «Résonances» (pp. 555-582), ha tuttavia voluto un «mariage blanc» (p. 565), amando Cendrars come un fratello, mossa da un senso di tenerezza per un uomo che, al loro primo incontro, si presenta in condizioni di estrema magrezza, «blanc, mais blafard» (p. 562), come nel celebre ritratto di Modigliani, e senza un braccio: il destro, quello con la mano della scrittura, perso sul fronte nel settembre 1915. Nella Préface, «Blaise et Raymone à corps perdu» (pp. 7-25), la curatrice del volume individua in questa corrispondenza una tripla portata - «l'Histoire l'amour l'écriture» (p. 13) - e sottolinea l'incompletezza di queste lettere: Cendrars gettava quelle ricevute dalla "femme aimée" («amoureuse à sa manière») non appena lette; la «Note éditoriale» (pp. 27-29) ci informa che le lettere sono dunque quelle «ayant 
échappé à la destruction volontaire» (p. 27). Gli originali, conservati nel Fonds Blaise Cendrars (Archives littéraires suisses della Biblioteca nazionale svizzera, a Berna), presentano di frequente difficoltà nella datazione delle carte, come varianti ortografico-sintattiche, o abbreviazioni nei nomi delle persone evocate, che Myriam Boucharenc sempre risolve con rigore critico. Questa corrispondenza - cui si devono aggiungere degli «Échos» (pp. 539-554), vale a dire le lettere che Cendrars ha scritto alla madre di Raymone, la sua cara «Mamanternelle» (la "mère éternelle") - si articola in tre grandi periodi: «De 1937 à 1940» (pp. 33-47), «De 1943 à 1947» (pp. 49-506) e «1954» (pp. 507-535).

2 Sono gli anni in cui Cendrars riscrive, a distanza di oltre trent'anni dall'esperienza vissuta, i propri souvenirs della prima guerra mondiale; ma anche quegli anni in cui, nel bel mezzo di un'altra guerra, egli si dedica a dei reportages che raccontano degli aneddoti, tracciano dei caratteri e dei ritratti dell'anima, mostrano la paura e le passioni degli uomini. Di tutto ciò troviamo un racconto intimo in queste lettere, dove Cendrars tocca argomenti disparati - dalle proprie malattie al tempo e al denaro -, rivolgendosi alla sua «chère Raymone», baciandola spesso «de tout cœur». 